\title{
GUITARRA ELÉTRICA: UM ÍCONE NA CULTURA POP DO SÉCULO XX
}

\author{
Neigmar de Souza ${ }^{l}$
}

\section{1 - Introdução:}

Já se falou muito em cultura pop e de seus ícones e muitos deles estão bem situados em nosso contexto cultural com artigos em revistas, jornais e também livros. Assim podemos falar da camiseta e da calça jeans que surgiram para o grande público através do cinema norte-americano dos anos $50^{2}$, pode-se falar do biquíni, da mini-saia, do chicle de bola, de Andy Warhol, Marilyn Monroe, refrigerantes e também drogas, maconha, LSD, cocaína e outras mais. Mas sobretudo podemos falar do rock que também ganhou público através do cinema norte-americano da década de $50^{3}$, transformando-se em um produto altamente consumido. $\mathrm{O}$ rock ajudou a mudar o comportamento social da juventude norte-americana a partir da segunda metade dos anos 50 e boa parte da juventude ocidental dos anos 60, revolucionou costumes profundamente arraigados: A maneira de vestir, o comportamento sexual e o consumo de drogas são alguns exemplos, mas também ostentava-se uma rebeldia que para muitos não tinha causa.

Como toda revolução tem seus líderes esta também tinha os seus, eram os atores jovens de Hollywood e os integrantes desses grupos musicais que começavam a ganhar cada vez mais espaço nos meios de comunicação tocando o novo ritmo. Os integrantes desse grupos que mais influenciaram a juventude foram os cantores (Elvis Presley por exemplo) e em segundo plano os guitarristas (Chuck Berry outro exemplo). A voz e a guitarra elétrica passaram a ser baluartes dessa juventude, no entanto a guitarra elétrica foi mais incisiva que a voz porque Elvis tinha como influência além do rythm n' blues dos negros o ídolo Frank Sinatra (que não via com bons olhos esta nova música) que representava outra geração, mas ninguém tocava guitarra como Chuck Berry e isso estava mudando esteticamente a música popular norte-americana. Mas Berry era negro talvez por isso a guitarra elétrica tenha ficado em segundo plano, depois fortemente influenciado por ele virá Jimi Hendrix, outro negro, mas com ele a guitarra elétrica vai ganhar status de ícone.

Nessa teia que é a cultura pop, vimos que faltavam estudos sobre a guitarra elétrica, que ocupa um lugar tão destacado nesse contexto quanto os já citados, é claro que existem publicações que falam dos "deuses" da guitarra, mas são textos frágeis com informações esparsas e falam mais do músico que do

\footnotetext{
'Graduação - Educação Artística (Música) - UFPR.

${ }^{2}$ Nos filmes "O Selvagem" e "Amor, Sublime Amor", nas figuras dos atores Marlon Brando e James Dean que foram os modelos para a nova maneira de vestir a juventude.

${ }^{3}$ Nos filmes "Sementes da Violência" (The Blackboard Jungle) e "No Balanço das Horas" (Rock Around the Clock).
} 
instrumento. A proposta deste artigo é justamente contar a história desse curioso instrumento e como ele se tornou ícone na cultura pop do século XX, tendo como ponto final o Monterey International Pop Festival realizado em 1967 na Califórnia, quando Hendrix exerceu o ritual do fogo na sua fender stratocaster.

\section{2 - Os Conjuntos Populares:}

A Enciclopédia Abril de 1972 que teve como consultores de música Júlio Medaglia, Walter Lourenção e Damiano Cozzela nos relata assim o crescimento dos conjuntos populares:

"A história do prestígio popular dos conjuntos musicais, sobretudo nos Estados Unidos, está fundamentalmente ligada ao surgimento do jazz em Nova Orleans, nas duas primeiras décadas do século XX. Inicialmente música restrita à comunidade negra, o jazz era conhecido por good-time music. Os primeiros conjuntos, surgidos por volta de 1900 , utilizavam instrumentos de percussão, semelhantes aos das bandas. Em recintos fechados, empregava-se mais o trio de instrumentos de cordas, geralmente formado de banjo, guitarra e bandolim.

Em 1917, com o fechamento de storyville, bairro de Nova Orleans destinado à prostituição legalizada, os músicos foram forçados a procurar novos lugares de trabalho, subindo o rio Mississipi em direção à Memphis, St. Louis e Chicago. Nessa época, Louis Armstrong introduz importante inovação no conjunto de jazz: a improvisação com base no solo de trumpete. Essa inovação abre caminho para o surgimento do trio, composto por piano, bateria e contrabaixo.

Na década de 20, o conjunto passou a ser veículo que introduzia e apoiava solistas. Além do conjunto menor, geralmente formado de trumpete, clarineta, trombone, piano e bateria, surgiria na década de 30 a grande orquestra (big-bands), que até o início da Segunda Guerra Mundial faria enorme sucesso, marcando a chamada "Era do Swing". Destacaram-se no período orquestras como as de Glenn Miller, Tommy Dorsey e Count Basie, formadas por piano, cordas, bateria, clarinetas, saxofones, trumpetes, trombones e guitarra.

No início da década de 50, o jazz e a música popular sofreriam grandes alterações com a introdução dos instrumentos elétricos. As grandes orquestras foram então substituídas por pequenos conjuntos de guitarra e baixo elétrico, piano e bateria. Ao mesmo tempo, o jazz retornava ao pequeno conjunto (piano, baixo, bateria e solista), criando o bebop, música que deixou de ser dançada, passando a ser feita exclusivamente para ser ouvida.

Os novos conjuntos elétricos, à procura de um som próprio, passaram a explorar as possibilidades dos instrumentos, assimilando o rhythm n' blues, música dos negros, de linha melódica poderosa. Nascia aí um gênero de grande sucesso, que, incorporado por artistas brancos, se tornaria conhecido 34 
com rock n' roll. Os conjuntos de rock multiplicaram-se e, convertidos em símbolo de rebeldia e inconformismo, foram durante algum tempo idolatrados por grande parte da população jovem americana.

Esse tipo de conjunto e de música evoluiria para o conjunto pop, que apareceu em meados da década de 60, utilizando sons e ritmos da África, instrumentos indianos, folclore americano, trombeta barroca, canto gregoriano, música eletrônica e colagens de ruídos de música concreta. Uma capacidade ilimitada de absorver estilos e instrumentos musicais mais marcantes."

Vol.III pg. 1075 e 1076, Vol.XII pg. 4818, 4819, 4820 e 4821.

\section{3 - A invenção da guitarra elétrica}

Existem várias versões para a invenção da guitarra elétrica, muitos tem sua importância e procuramos citar os nomes que mais contribuíram para o desenvolvimento do instrumento junto com algumas curiosidades, mas antes falaremos sobre o nome guitarra que pode gerar alguma confusão. Quando falamos em guitarra associamos o nome ao instrumento elétrico imortalizado pelo rock, porém, principalmente nos países latino americanos de língua espanhola e consequentemente a própria Espanha, guitarra tem o mesmo sentido do nosso violão. A raiz etimológica de guitarra remonta a kítara de origem caldéia-assíria que se transformou, na Idade Média, em guitarra, guiterre, guiterne, guithern e guitar. ${ }^{4}$

Também queríamos esclarecer que este trabalho não vai abordar as guitarras "semi-acústicas" ou "eletro-acústicas" e nem as desconhecidas guitarras "semi-sólidas" que antecederam em alguns anos as guitarras elétricas de corpo maciço, é a partir delas que vamos iniciar os nossos estudos. Ou talvez um pouquinho antes.

Conforme o livro "O Design do século (XX)" de Michael Tambini (Ed. Ática, 1999), um projeto foi desenvolvido em 1932 com o nome de Rickenbacker Electro Spanish:

“O ressonador (que já havia sido desenvolvido pelos irmãos Dopyera em meados da década de 20) foi uma das soluções encontradas para aumentar o volume, a outra foi amplificar o som eletricamente, muitas pessoas participaram do desenvolvimento do projeto, esta tentativa inicial possivelmente a primeira guitarra eletroacústica - foi projetada também pelo suíço (Adolph Rickenbacker) e deve ter sido fabricada para ele sob encomenda pela Harmony Company de Chicago.” Pg. 166

\footnotetext{
${ }^{4}$ Dudeque, Norton. História do Violão. Curitiba: 1994. Editora: UFPR, p. 09.
} 
A revista Áudio News, (Ano IV, $\mathrm{N}^{\circ}$ 53) de abril de 1996 em reportagem de Cláudio Julio Tognoli, dá a seguinte nota:

"A primeira guitarra elétrica foi desenvolvida em 1934 por Adolph Rickenbacker e George Beauchamp, o inventor do captador magnético ${ }^{5}$. A patente para esse modelo Fry Pan (frigideira) saiu em agosto de 1937.” Pg. 47

Porém o livro "The Guitar Handbook" (Rio Gráfica e Editora Ltda, 1983) de Ralph Denyer, nos esclarece melhor esta história:

"O desenvolvimento da guitarra "elétrica" verdadeira (maciça e não com caixa acústica) se deve em grande parte à popularidade da música havaiana nos Estados Unidos, durante as décadas de 20 e 30. Guitarras havaianas são instrumentos em que as diferentes notas não são obtidas pelo pressionamento da corda contra os trastes, mas fazendo-se um cilindro metálico liso deslizar por sobre as cordas. As guitarras havaianas elétricas foram os primeiros instrumentos produzidos comercialmente cujo som dependia quase totalmente de amplificação elétrica e não apenas acústica.

Uma das principais figuras em seu projeto foi Adolph Rickenbacker, que havia sido contratado para fabricar componentes metálicos para os violões "Dobro", da National. Na National ele conheceu George Beauchamp e Paul Barth, que trabalhavam no princípio do captador magnético. Juntos criaram a Electro String Company e, em 1931, produziram as primeiras guitarras havaianas elétricas - A-22 (que ficou conhecida como "frigideira" ou panqueca") e A-25. Os números 22 e 25 se referem ao comprimento de escala, em polegadas... $O$ sucesso dessas guitarras levou outros fabricantes - como a Gibson ${ }^{6}$ e a National/Dobro - a produzirem instrumentos equivalentes. Por volta de 1940, os violões elétricos Gibson já estavam firmemente estabelecidos, e não é de surpreender que muita gente estivesse tentando usar o corpo maciço na construção de guitarras.” Pg. 42

Porém havia um problema, os músicos norte-americanos que tocavam os instrumentos eletroacústicos reclamavam da microfonia ${ }^{7}$ e ninguém conseguia resolvê-lo satisfatoriamente. O então guitarrista de jazz e mais tarde afamado radialista nos EUA Les Paul (Lester William Polfus, EUA 1915) foi outro pioneiro em projetos de guitarras elétricas, tocava uma quase que primitiva em 1928 usando o rádio de seus pais como amplificador. A exemplo de Leo Fender, Les Paul também

\footnotetext{
${ }^{5}$ Captador ou "Pick up": é o captador de som na guitarra elétrica, equivalente à agulha no toca-discos.

${ }^{6}$ Gibson Mandolin-Guitar Manufacturing Co. Fundada em 1902 por Orville Gibson, tornou-se um dos maiores nomes no design e fabricação de guitarras. Nos anos 40 a fábrica dominava o mercado de violões eletrificados nos EUA e se orgulhava da tradição artesanal da produção de seus instrumentos.

${ }^{7}$ ou feedback - apito que ocorre em amplificadores ligados em instrumentos com caixa de ressonância ou efeito de retroalimentação na guitarra, quando ela reproduz o próprio som e dá efeitos de distorção.
} 
procurava resolver os problemas de feedback, Ralph Denyer esclarece como ele resolveu este problema:

“...problemas de ressonância e feedback. Foi quando ele ouviu falar do violino maciço feito pelo inventor americano Thomas Edison - o que o fez pensar em construir uma guitarra maciça. Les Paul estava convencido de que a única maneira de evitar a ressonância e o feedback seria reduzindo os movimentos do captador - e a única forma de conseguir isso seria montá-lo sobre uma peça sólida de madeira.” Pg.42

Foi acreditando neste conceito que Les Paul criou em 1941 o protótipo do que poderia ser a primeira guitarra de corpo sólido do mundo que batizou de log (tronco, lenho) ${ }^{8}$., ele persuadiu a Epiphone (empresa concorrente da Gibson na fabricação de violões elétricos na década de 1940 até ser comprada pela mesma Gibson em 1957) a permitir que usasse suas oficinas aos domingos. Ali ele construiu sua célebre guitarra "log" (tora), a respeito da qual disse mais tarde: "Podia-se sair para comer $e$, ao voltar, a nota ainda soava. Não soava como um banjo ou um bandolim, mas como uma guitarra, uma guitarra elétrica". $\mathrm{O}$ protótipo foi levado posteriormente para a Gibson porém o projeto causou risos entre os diretores que o arquivaram, realizado somente 10 anos depois e lançado no mercado em 1952 com um belo acabamento dourado, o pequeno projeto transformou-se em um instrumento quase místico para muitos músicos, foi assim que nasceu em 1951 a Gibson Les Paul.

Esses dez anos foi o tempo mais que necessário para surgir um outro nome significativo no mercado de guitarras elétricas, Leo Fender. Na década de 40 os músicos de country ${ }^{I O}$ e blues possuíam um ordenado modesto e não podiam comprar os instrumentos sofisticados da Gibson, que servia aos já conceituados músicos de jazz., Denyer novamente nos explica como era a vida de Fender naqueles anos:

"Em 1944, Leo Fender - que tinha uma oficina de consertos de rádio - associou-se a "Doc" Kauffmann, ex - empregado de Rickenbacker, para criar a companhia K \& F. Produziram uma série de amplificadores e steel guitars (instrumento semelhante à guitarra havaiana). Leo julgava, acertadamente, que os pesados imãs dos captadores usados então não precisavam ser tão grandes. Para experimentar um novo captador que projetou, montou-o numa guitarra maciça, cuja forma se baseava na guitarra havaiana, mas que tinha escala com trastes, como na guitarra normal. $O$ instrumento deveria apenas servir como demonstração para a eficiência do

\footnotetext{
${ }^{8}$ Revista Cover Guitarra $\mathrm{n}^{\circ} 62$ janeiro de 2000, pg. 34 .

${ }^{9}$ Denyer, Ralph, "The Guitar Handbook" Rio Gráfica e Editora Ltda. Rio de Janeiro, 1983. Pg.42

${ }^{10}$ Eldon Shamblin do grupo Bob Will's Texas Playboys foi o primeiro músico country a tocar uma guitarra de corpo sólido em 1937 nos EUA.
} 
captador - mas logo passou a ser muito procurado por músicos country locais. Na verdade, tornou-se tão popular que havia uma lista de espera de pessoas que desejavam alugá-lo. Quando Leo e "Doc" Kauffmann romperam a associação em 1946, o primeiro formou sua própria empresa, a Fender Eletric Instrument Company." Pg.42

Depois que o vendedor Charles Hayes fez o pedido por volta de 1948, Leo Fender começou a trabalhar seriamente no seu primeiro design de um instrumento que pudesse atender essa clientela. Fender possuía uma pequena loja de consertos de instrumentos e rádios em San Francisco, Califórnia, da qual era o único funcionário.

Outro problema que tirava o sono de Leo eram as insistentes reclamações dos músicos com relação a microfonia, decidiu que resolveria esse problema de uma vez por todas. Esse foi o começo da Esquire, que depois virou Broadcaster, e que finalmente virou a fender telecaster. Esse instrumento resolveu os dois problemas, não haveria mais microfonia por ser maciço, e atenderia a uma clientela sem muitos recursos, um produto bom e barato. Não é preciso dizer que a idéia vingou, a pequena loja de Fender passou a contar com mais funcionários e de consertos passou a ser fabricante de um novo instrumento que se tornou mania entre os músicos de country e blues. O crescimento foi tanto que os diretores da Gibson precisaram rever seus produtos e alguém lembrou-se de um antigo projeto que possuía as mesmas características do instrumento da Fender.

Em 1952, com a entrada da Gibson Les Paul no mercado as coisas voltaram a ser como antes, ou seja a Gibson voltou de certa maneira ao domínio, seus instrumentos tinham (e ainda têm) ótima qualidade além da já adquirida tradição. Em reportagem sobre a história das guitarras Fender Richard Smith ${ }^{11}$ faz o seguinte comentário sobre o assunto:

"Para Don Randall, presidente da distribuidora Fender Sales, para Leo Fender conseguir manter uma posição mercadológica firme significava adicionar um modelo novo e apropriado a linha. Para Leo a nova guitarra era uma faca de dois gumes: ao mesmo tempo que era uma produto novo e de melhor qualidade, iria contribuir para desgastar a imagem da telecaster, que era um sucesso, lançada em 1954 a stratocaster representava para Leo progresso, renovação, mas também vaidade."12

De qualquer forma Fender se superou, seu instrumento teria o mais profundo e duradouro efeito. Seu design permanece o mesmo desde o lançamento,

\footnotetext{
${ }^{11}$ Freqüientador assíduo das páginas da revista Guitar Player norte-americana, Richard Smith é o autor de "The History of Rickenbacker Guitars (Centerstream)" e do livro autorizado pela Fender "The Sound Heard Around the World", dos quais partes deste texto foram retiradas.

${ }^{12}$ Revista Guitar Player em Português, Ano 1, No 09, setembro de 1996, pag.66. 
até hoje considerada como a mais popular e mais copiada guitarra, é o modelo de instrumento musical mais vendido em toda a história.

O pesquisador Edson Franco Pinto em reportagem para a revista "Showbizz Especial, Grandes guitarristas de todos os tempos. Ed. 02 de novembro de 1997" faz o seguinte comentário sobre o aparecimento da fender stratocaster:

"Era muita revolução para os músicos dos anos 50, três captadores (as outras tinham um ou dois), uma alavanca feita sob medida (as outras adaptavam seus modelos à alavanca produzida por uma outra empresa, a Bigsby ${ }^{13}$ ), saída de cabo na frente do corpo e ajuste de altura para cada uma das seis cordas. A fender stratocaster só encontrou um período de queda de vendas, foi entre 1963 e 1966 quando George Harrison e John Lennon transformaram guitarras Epiphone e Rickenbacker em objeto de culto e de vendas."

Era o auge da beatlemania.

Uma das curiosidades é que no Brasil também houveram pesquisadores, em entrevista à Luciano Marsiglia e Alexandre de Almeida da revista Guitar Player em Português (Ano 1, $\mathrm{N}^{\circ} 09$ de setembro de 1996) Armandinho ${ }^{14}$ nos conta um pouco desta história:

"A primeira vez que Dodô e Osmar ouviram falar de um instrumento elétrico foi em 1942 (um ano após o primeiro projeto de Les Paul), com o Benedito Chaves, que era apresentado como Benedito Chaves e seu violão elétrico, na verdade o que ele tinha era só um captador, Dodô conseguiu um diagrama técnico desse captador e passou a construí-lo, colocando nos instrumentos acústicos. Mas nas festas havia o problema da microfonia (o mesmo problema de Fender e Les Paul). Osmar percebeu que tampando a boca do instrumento diminuía a microfonia e resolveu fazer um instrumento de madeira maciça (mesma solução de Fender e Les Paul). Pegou um pedaço de madeira, colocou um parafuso em cada lado, o captador e apertou as cordas, aumentou todo o volume e não deu microfonia, Eureka! $\mathrm{O}$ instrumento era um pau mesmo, só o braço era de cavaquinho, mas eles não tinham conhecimento de patente e não registraram o novo instrumento. Em 1950, a orquestra de

\footnotetext{
${ }^{13}$ Em 1947, Paul Bigsby (inventor da alavanca de trêmolo, que é na realidade um nome incorreto para um dispositivo que consiste numa unidade de vibrato. $\mathrm{O}$ efeito de trêmolo refere-se à mudança rápida $\mathrm{e}$ regular do volume de uma nota. $\mathrm{O}$ vibrato é uma variação rápida e regular da frequiência de vibração de uma nota.) construiu uma guitarra elétrica maciça, projetada com assessoria do famoso guitarrista Merle Travis. Na verdade, Bigsby e Travis construíram sua guitarra na Califórnia não muito longe do centro de operações da Fender em Fullerton. Esse conjunto de circunstâncias deu origem a controvérsias quanto a quem teria copiado quem. Certamente, Leo Fender não mantinha segredo sobre seu trabalho: na década de 40, sua oficina foi visitada por Les Paul e por outros. Denyer, Ralph. "The Guitar Handbook" Rio Gráfica e Editora Ltda, Rio de Janeiro, 1983. Pg. 15 e 42.

${ }^{14}$ Músico baiano que ganhou fama por tocar um instrumento chamado "pau-elétrico" (depois batizado.de guitarra baiana), chegou a tocar no badalado Festival de Montreaux e integrou o grupo A Cor do Som.
} 
frevo de Pernambuco esteve em Salvador, saíram para a rua, começou o frevo a multidão enlouqueceu! Daí veio a idéia do trio elétrico. Na época os desfiles não eram com música, e Dodô e Osmar resolveram ligar os instrumentos na bateria do carro, quando começaram a tocar foi uma loucura, arrastaram a multidão, chegou uma hora em que o carro quebrou e a multidão empurrava. A polícia apareceu e mandou parar. Aí o motorista falou: - Não estou dirigindo, só estou na direção... No ano seguinte, a festa foi em cima de uma caminhonete, depois uma empresa de refrigerante contratou Dodô e Osmar e eles começaram a sair com um caminhão, com iluminação.” Pg.52

Nascia ali a guitarra baiana e o trio elétrico.

Falando um pouco mais sobre a guitarra elétrica no Brasil a revista Cover guitarra (Ano $06 N^{\circ} 62$ de janeiro de 2000) fez um interessante estudo sobre o instrumento no século XX, guardando um espaço para as guitarras nacionais o qual reproduzimos aqui:

"Sendo um dos pioneiros na fabricação de violões no Brasil, Tranquilo Giannini chegou ao Brasil no final do século XIX, com apenas 20 anos. A partir de uma pequena loja/fábrica inaugurada em 1900, a marca Giannini só começou a fabricar suas guitarras na primeira metade da década de 60, com a chegada da beatlemania no Brasil. Os dois primeiros modelos ambos lembrando, respectivamente, a Fender Stratocaster e a Gibson Les Paul, serviram como os primeiros instrumentos de milhares de guitarristas cujas carreiras iniciaram o que se chamou de "Jovem Guarda", pedra fundamental para o surgimento do rock brasileiro.

Angelo Del Vecchio, que chegou ao Brasil dois anos depois que Giannini, montou sua primeira loja em 1903. Mas foi a partir da década de 30, quando foi inaugurada sua fábrica, que ele passou a exercer o ofício aprendido na Itália (onde foi auxiliar na construção de violões). Também com a chegada da beatlemania, a Del Vecchio começou a construir suas próprias guitarras, com a diferença de que procuravam criar modelos próprios, como o twist, que já vinha com uma rudimentar alavanca de vibrato. A marca se retirou do mercado na década de 70.” Pg.53

Outro nome que merece ser citado é Cláudio César Dias Baptista irmão mais velho de Sérgio e Arnaldo, os irmãos que com Rita Lee formaram o grupo "Os Mutantes" em meados da década de 60. Cláudio César fabricava as guitarras, baixos, e manuseava todo o equipamento de som da banda, sendo um dos primeiros profissionais da área no Brasil. 


\section{3- A construção do Mito}

Na segunda metade dos anos 50 nos salões de festas dos Estados Unidos, de repente deixou-se de estalar os dedos para atirar a parceira na direção do teto do salão ou sacudir a cabeça até o torcicolo. Era um novo ritmo que Alan Freed, um disc-jóquei de Cleveland, Ohio, percebeu na música negra e que daria um bom filão mercadológico consumível pelo branco, desde que trocasse o nome de rhythm n' blues, demasiadamente negro, por algo mais branco, nascia ali o rock n' roll união de duas gírias de conotação sexual. Os ídolos do novo ritmo são músicos menos sofisticados que os de jazz, entre eles destacam-se Bill Haley, Little Richard e Elvis Presley que justamente vão explorar a imagem de Sex simbol ou da libido. Elvis será a imagem de Bill Haley mais moço, já que este era um tanto avançado na idade para o papel sexy, e será responsável pelos desmaios de fãs histéricas, Little Richard vai explorar mais a questão da ambigüidade sexual, mas o personagem que mais interessa nesse momento para nós chama-se Chuck Berry. O site http://www.lostinrock.com.br conta assim a história desse curioso pop star:

"Charles Edward Anderson Berry nasceu em 18 de outubro de 1926 em St. Louis, Missouri. Se iniciou na música participando de corais evangélicos influenciado pelo pai pastor protestante, curiosamente apenas na década de $\mathbf{4 0}$ Berry teve contato com a guitarra, pouco antes de passar uma temporada em um reformatório juvenil por furto. Em 1952 Berry tocava profissionalmente em uma banda de country-blues, a medida que o guitarrista se destacava como atração principal dos palcos onde tocava o nome do grupo foi mudado para Chuck Berry Combo, participavam da banda Johnnie Johnson (piano) e Eddie Hardy (bateria). O destino sorriu para Berry na figura de Muddy Waters, antigo ídolo e sua principal influência. Waters recomendou a Berry que procurasse a Chess Records para gravar um single. Com o apadrinhamento de Muddy Waters poucas semanas depois Chuck Berry gravou (com Willie Dixon no piano) duas músicas, Ida May (pouco mais tarde regravada como Maybellene) e Wee Wee Hours. O single chegou ao número cinco nos Estados Unidos, era o começo do sucesso. Menos de um ano depois Berry já vendia mais discos que todo o "staff" da Chess somado. Boa parte do sucesso se deveu a sua incrível presença de palco, mais do que cantar Berry tocava guitarra como um demônio, gesticulando, correndo e fazendo o seu clássico "duck-walk". ${ }^{15}$ Era mais do que um cantor, músico ou poeta, Chuck Berry foi o primeiro artista de rock completo."

Sua guitarra era uma Gibson 335 .

15 "andar de pato"- Berry caminhava como um pato enquanto tocava. 
Essa explosão do novo ritmo aumenta sem dúvida a venda de guitarras elétricas e parece ser Chuck Berry o primeiro grande responsável por isso, principalmente junto aos novos músicos que vêm, ouvem e dançam o rock, sem saber que está se formando uma indústria milionária.

Citando novamente Richard Smith em reportagem para a revista "Guitar Player em Português ano $1, n^{\circ} 09$ de setembro de 1996" veremos como ele descreve o relacionamento dos músicos norte-americanos com as diversas marcas de guitarras elétricas existentes no mercado, e também o surgimento de mais uma invenção de Leo Fender:

"Para a maioria dos jovens músicos dos anos 50 que estavam começando, os degraus mais altos da escada, depois de uma fender telecaster ou uma stratocaster, eram as Gibson, Gretsch, ou Epiphone. Os catálogos e os anúncios da época mostravam os virtuosos Herb Ellis, Jim Hall, Barney Kessel, George Barnes, Tal Farlow e Tony Mottola divulgando as Gibson Super 400, L5 e $E$-350. Os rostos sérios desses músicos contrastavam com o sorriso de garoto do promotor da Fender Buddy Merrill. Para atender o mercado de ponta dos anos 50, Leo sentiu-se obrigado a projetar uma guitarra de jazz. Era a maneira lógica de expandir antes do "boom" das bandas de rock que viria a seguir... A jazzmaster foi um fracasso, a vaidade tornou-se mais importante à medida que Leo queria convencer o mundo da guitarra que corpos maciços não eram apenas iguais, mas superiores aos das semi-acústicas. Fazendo isso, ele se desviou da fórmula que havia tornado as primeiras guitarras tão bem sucedidas... Joe Pass era o único guitarrista de jazz conhecido a gravar com uma jazzmaster, que rapidamente foi reprovada na maioria dos testes em estúdios profissionais... As jazzmaster certamente tiveram seu lugar, mas não no palco que Leo pretendia, talvez o nome mais apropriado para o modelo fosse Garagemaster $^{16}$...” pg.69, 70.

Leo Fender ainda não tem muita competitividade mas percebe-se um crescimento significativo na sua produção, assim explica Richard Smith na mesma reportagem:

"De maio de 1954 a dezembro de 1955, a fábrica fez 658 Telecaster e 369 Esquire, num total de 1.027 guitarras. Para a surpresa de Leo, a Stratocaster não tirou a Telecaster do mercado. Aí ele percebeu que havia criado um produto que levaria algum tempo para ser apreciado e comprado pelo músico médio, mas que acabaria se tornando seu maior sucesso.” Pg. 69

\footnotetext{
${ }^{16}$ Alusão feita ao uso das "Jazzmaster" por bandas de rock chamadas posteriormente de bandas de garagem, um exemplo foi Kurt Cobain do grupo Nirvana, que usava uma guitarra desse modelo que fez muito sucesso nos anos 1990 com um movimento chamado "grunge".
} 
Com a chegada do rock a indústria de guitarras elétricas de corpo sólido se estabelece, as guitarras semi-acústicas estão bem no mercado de jazz. O rock vai ser um fenômeno, primeiro com Elvis depois com a beatlemania, e as guitarras elétricas de corpo sólido aumentarão muito em vendas, porém o mito ainda vai demorar um pouco mais para se consolidar.

\section{4- Monterey International Pop Festival: $O$ ponto final.}

É fácil notar que os músicos de rock são menos sofisticados que os de jazz, porém Chuck Berry está causando furor, Elvis então nem se fala, mas Chuck faz com seu instrumento algo diferente, sua performance é diferente, o rock vai se tornando um verdadeiro incêndio e toma conta da música pop em boa parte do mundo. Há cada vez mais investimento na nova música e depois dos Beatles a indústria ficou milionária. A história do rock de 1955 a 1967 é chamada de primeira fase, Chuck Berry, Elvis Presley, Little Richard e Jerry Lee Lewis são os ícones desse primeiro período, os adolescentes que ouviram esses ídolos já cresceram e estão trilhando o mesmo caminho, os Beatles já existem, mas Jimi Hendrix, Janis Joplin, The Who, e outros mais vão aparecer no festival de Monterey, em 1967.

$\mathrm{O}$ historiador Roberto Muggiati no livro "Rock: Da utopia à incerteza (1967 - 1984)" nos conta um pouco desse festival:

"Inspirado nos festivais de jazz e folk (que existiam desde os anos 50 e que geralmente atraíam públicos de 5 a 10 mil pessoas) o de Monterey apesar dos esperados 7.100 acabou tendo de acolher $50 \mathrm{mil}$, a maioria sem ingresso. $O$ importante era estar lá, fiel ao slogan do festival, "Música, amor e flores". O festival aconteceu no fim de semana de 16 à 18 de junho daquele ano. Próxima de San Francisco, na Califórnia, Monterey atraiu não só os grupos hippies sanfranciscanos, mas também seus melhores conjuntos de rock. Antes curiosidade local, estes conjuntos agora ganhavam fama no país e no mundo, graças a cobertura dada pela imprensa." Pg.08.

O site http://www.ultimapágina.com.br nos diz porque o festival foi um sucesso:

"O festival de Monterey foi sucesso porque contou com especialistas na produção, como John Phillips, do grupo The Mamas and The Papas, David Crosby, Andrew Loog Oldham, empresário dos Rolling Stones, Paul Simon, e Paul McCartney. Participaram do festival nomes como: Grateful Dead, Jefferson Airplane, The Who, Eric Burdon and The Animals, Canned Heat, Country Joe and The Fish" 
E novamente recorremos à Roberto Muggiati para mais detalhes sobre o evento:

"É impressionante a reverência quase mística com que o público acompanha a apresentação de Ravi Shankar, tocando uma raga indiana adequada àquele momento. Mas o principal em Monterey Pop é que mostra, em imagens impressionantes, o nascimento instantâneo de duas estrelas do rock: Janis Joplin e Jimi Hendrix. Este festival foi documentado no filme Monterey Pop de D.A Pennebacker.’' Pg.09

A história e a influência de Jimi Hendrix (ver anexo) na música pop daria um outro trabalho, ou com um pouco mais de cuidado um bom livro, mas deixemos isto para outra oportunidade, o que importa aqui é que antes do festival de Monterey Jimi estava na Europa levado por Chas Chandler, que o recebeu por indicação de Linda Keith (acompanhante de Keith Richard) para transformá-lo em pop star. Jimi está em excursão pelo velho mundo com o seu desconhecido grupo The Jimi Hendrix Experience, que contava com Noel Redding e Mitch Mitchell, mas isso não quer dizer que as apresentações não causem repercussão, Muggiati nos fala um pouco mais sobre isto:

"Em Munique, durante uma invasão do palco por fãs histéricas, Jimi cai sobre a guitarra e a esmaga. Ele recolhe o que resta do instrumento e se põe a quebrá-lo contra as caixas de som. A partir de então o sacrifício das guitarras se torna um ritual obrigatório em seus shows. Num outro concerto, em Londres, Jimi se supera ateando fogo na guitarra (uma fender stratocaster), o visual de suas apresentações vai se enriquecendo." Pg. 16 e 17

Levado pelo empresário dos Rolling Stones, Andrew Loog Oldham, para o festival de Monterey Jimi Hendrix vai se apresentar por último, logo depois da explosão de som e fúria do The Who. Mas ele vai superar o grupo inglês em impacto e violência, emprestamos novamente as palavras de Muggiati:

"Recém chegado da swinging London, com suas roupas coloridas, calça justa, camisa cheia de pregas com mangas bufantes, colete de veludo indiano, cabelos afros presos por uma fita na testa, ostentando um ar de cigano e fortemente influenciado por Chuck Berry, ele acaricia a guitarra, finge que faz amor com ela, toca nas costas e com os dentes, levando a influência de Berry a décima potência, depois a sacrifica num ritual de fogo, aspergindo-a com fluido de isqueiro, incendiando-a e deixando que se consuma em meio às chamas, gemendo atrás dos amplificadores a todo volume suas últimas notas antes de se transformar em cinzas. É uma cena dramática.” Pg. 09 e 10. 
O festival de Monterey foi o primeiro em que a intensidade do rock veio a tona, na verdade era um grande presságio do que estaria por vir, o festival de Woodstock foi o ponto culminante, o festival de Altamont o reverso, e Jimi Hendrix morreu dias depois do festival da Ilha de Wight em 1970 envolto em mistério. É claro que tudo isso ainda requer maiores esclarecimentos, mas a proposta deste artigo era apenas contar a história da guitarra elétrica e como ela se tornou ícone na cultura pop do século XX..

\section{Bibliografia:}

BAHIANA, A. M. - Jimi Hendrix, brasiliense - São Paulo, 1984.

CHACON, P. - O que é Rock, brasiliense - São Paulo, 1983.

DENYER, R. - The Guitar Handbook, Rio Gráfica e Editora Ltda. - Rio de Janeiro, 1983.

DUDEQUE, N. - História do Violão, Editora UFPR - Curitiba, Pr. 1994.

ENCICLOPÉDIA, Abril. Ed. Abril S/A - São Paulo, 1972

MUGGIATI, R. - Rock, da utopia à incerteza (1967-1984), brasiliense -

Paulo, 1985.

REVISTA, Áudio News - Ano IV - n 53, Sigla Editora - São Paulo, 1996.

REVISTA, Cover Guitarra - Ano 06 - n62, Jazz Editora - São Paulo, 2000.

REVISTA, Guitar Player (em português) - Ano I - nº 09, Trama Editora - São Paulo, 1996.

TAMBINI, M. - O Design do século (XX), Ed. Ática - Rio de Janeiro, 1999. 